LWSA

Local Wisdom, Social, and Arts

PAPER - OPEN ACCESS

\title{
Rumah Tradisional Desa Budaya Lingga di Kabupaten Karo dalam Perspektif Pariwisata Budaya
}

\author{
Author \\ : Asmyta Surbakti \\ DOI \\ : 10.32734/lwsa.v1i1.154 \\ Electronic ISSN \\ : 2654-7058 \\ Print ISSN \\ : 2654-7066
}

Volume 1 Issue 1 - 2018 TALENTA Conference Series: Local Wisdom, Social and Arts

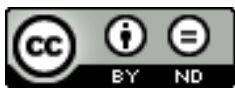

This work is licensed under a Creative Commons Attribution-NoDerivatives 4.0 International License.

Published under licence by TALENTA Publisher, Universitas Sumatera Utara
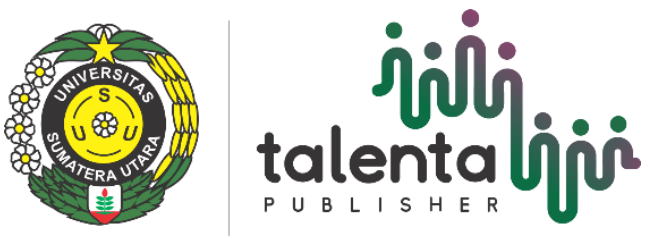


\title{
i talenta i̊ji̊ TALENTA Conference Series \\ Available online at https://talentaconfseries.usu.ac.id \\ Rumah Tradisional Desa Budaya Lingga di Kabupaten Karo dalam Perspektif Pariwisata Budaya
}

\author{
Asmyta Surbakti ${ }^{\mathrm{a}}$, Mahmud Arief Albar ${ }^{\mathrm{a}}$ \\ Fakultas Ilmu Budaya, Universitas Sumatera Utara, Medan-20155, Indonesia \\ mita_surbakti@yahoo.com,iostars@yahoo.com
}

\begin{abstract}
Abstrak
Desa Budaya Lingga di Kabupaten Karo memiliki empat bangunan tradisional Karo yaitu bangunan Rumah Gerga, Belang Ayo, Sapo Ganjang, dan Griten. Sejak tahun 1980an Desa Lingga telah dijadikan ODTW favorit di Tanah Karo dan termasuk paling sering dikunjungi wisatawan mancanegara. Namun, mulai tahun 2000an terjadi penurunan wisatawan karena bangunan hancur satu persatu. Pada tahun 2012-2014 keempat rumah tradisional ini dikonservasi oleh Badan Warisan Sumatera atas dukungan World Monument Fund. Desa Budaya Lingga sebaiknya dikembangkan mengikuti segmentasi pasar pariwisata global, yaitu pariwisata budaya. Desa Lingga merupakan bukti tingginya peradaban nenek moyang masyarakat Lingga dan juga untuk mempersiapkan keterlibatan masyarakat dalam menghadapi MEA 2015. Dalam penelitian ini digunakan deskriptif-kualitatif. Metode pengumpulan data diperoleh dari survey, observasi, dan metode kepustakaan. Data primer diperoleh melalui wawancara mendalam, observasi-partisipasi, dan teknik dokumenter. Metode pengumpulan data dan strategi analisis data menggunakan model deskriptif-kualitatif dari Bungin (2007) disertai analisis SWOT yang sesuai dengan konsepsi Sun Tzu. Hasil penelitian disajikan secara informal melalui deskripsi induktif-analitik dan dilengkapi dengan penyajian formal. Kesimpulan hasil penelitian didasarkan pada deskripsi kata-kata dibantu penyajian formal.Hasil penelitian menunjukkan bahwa Desa Lingga memiliki potensi besar untuk dikembangkan sebagai ODTW pariwisata budaya. Diperlukan pemberdayaan masyarakat Desa Budaya Lingga dalam mengembangkan objek wisata rumah tradisional Karo di Desa Lingga sebagai bentuk peran serta masyarakat dalam pariwisata. Masyarakat perlu penyegaran terkait isu-isu pariwisata global, yaitu pengembangan Pariwisata Budaya dan sosialisasi Tourism Based-Community Development. Akhirnya, hasil penelitian bermanfaat bagi Pemerintah Kabupaten Karo dalam membangun kepariwisataannya, mengembangkan ekonomi kreatif dan pemberdayaan masyarakat lokal dalam pengelolaan ODTW pariwisata budaya.
\end{abstract}

Kata Kunci: Desa Lingga, Pariwisata Budaya, Ekonomi Kreatif, Pemberdayaan Masyarakat, MEA 2015

\section{Pendahuluan}

Desa Budaya Lingga di Kabupaten Karo memiliki empat bangunan tradisional Karo yang indah dan penuh dengan ornamen beraneka warna. Keempat bangunan tersebut terdiri atas Rumah Gerga yaitu rumah tempat tinggal raja, Rumah Belang Ayo yaitu rumah masyarakat biasa, Sapo Ganjang untuk tempat penyimpanan padi, dan Geriten yaitu tempat menyimpan tulang belulang leluhur. Pada tahun 2012 keempat bangunan tradisional ini dikonservasi Badan Warisan Sumatera (BWS), keseluruhan biaya ditanggung oleh World Monument Fund (WMF) di Amerika dan konservasi ini rampung dilaksanakan pada bulan Januari 2014. Setelah upaya konservasi selesai, BWS mengajukan usulan agar hasil konservasi dimasukkan ke dalam Program Nasional Pemberdayaan Masyarakat (PNPM). Akan tetapi, usulan itu tidak ditindaklanjuti dan rumah tradisional dalam keadaan terbengkalai. 
Pada tahun 1080an Desa Budaya Lingga merupakan sebuah objek favorit wisatawan mancanegara. Rumah tradisional Karo yang besar dengan arsitektur unik, dipenuhi ragam hias dalam pelbagai warna dan bentuk membuat Desa Lingga menempati tempat pertama dalam urutan minat wisatawan. Sarana dan prasarana pariwisata dalam keadaan baik dan lengkap. Sebenarnya pada tahun1970an terdapat sekitar 29 buah rumah tradisional Karo di Desa Lingga dengan dua jenis rumah yaitu rumah kurung manuk dan rumah sendi atap ertingkat. Rumah Gerga yang masih ada merupakan rumah keturunan Maharaja Agi Sry Timur Raja dari Linggaraja (Putro, 1997). Banyaknya sebaran rumah tradisional tersebut merupakan bukti sejarah panjang serta tingginya peradaban nenek moyang masyarakat Desa Lingga.

Pemanfaatan rumah tradisional sebagai objek wisata sekarang ini mendapat perhatian Pemerintah Indonesia. Dengan kebijakan itu, Pemkab Karo mendata rumah tradisional Karo yang tersisa di Kabupaten Karo dan melakukan upaya-upaya pelestarian atasnya. Tidak banyak lagi yang tersisa dan yang paling baik keadaannya berada di Desa Lingga. Sebelum era Kolonial Belanda Desa Lingga menganut sistem pemerintahan berbentuk kerajaan yang kaya, rakyatnya makmur, dan berbudaya tinggi (Ginting, 2002). Namun, setelah dikonservasi rumah tradisional Lingga dapat dikatakan dalam keadaan terbengkalai tidak ada tindaklanjut pemanfaatannya.

Objek wisata Desa Lingga sekarang mengalami degradasi, kondisi desa sangat sepi dari aktifitas pariwisata. Fasilitas pariwisata pada umumnya dalam keadaan terbengkalai dan sumber daya manusia yang ada mulai berkurang sedikit demi sedikit. Padahal angkutan umum pariwisata disediakan pemerintah setempat dengan trayek Desa Lingga-Gunung Sibayak-Raja Berneh untuk melayani para wisatawan mancanegara dan lokal. Ketiga lokasi favorit di Kabupaten Karo ini diharapkan dapat meningkatkan geliat kepariwisataan Tanah Karo yang sedang lesu.

Kurangnya informasi tentang isu-isu dan kecenderungan kepariwisataan global di jajaran pegawai Dinas Pariwisata Kabupaten Karo, seperti pariwisata budaya (Cultural Tourism), dan juga lemahnya pemahaman masyarakat terhadap pengembangan pariwisata membuat geliat pariwisata di Lingga cenderung menurundari tahun ke tahun.Setelah dikonservasi tidak ada peningkatan wisatawan karena masih sampai pada perbaikan fisik objek semata. Padahal potensi besar sumber daya alam, sumber daya budaya seperti sejarah, arsitektur tradisional, seni tradisional, dan kerajinan terdapat di desa ini. Produk barang-barang kerajinan Desa Lingga, khususnya dalam bidang seni, selalu lebih diminati karena lebih indah dengan kualitas prima.

Potensi sumber daya budaya dan sumber daya alam Desa Lingga, menurut istilah Bordieu, merupakan modal yang sangat besar yang disebut sebagai modal budaya (Cultural Capital) (Harker, et al, eds., 2005). Hal ini disimpulkan dari analisis sosiologis konsumsi pariwisata bila dikaitkan dengan keinginan wisatawan, sehingga permasalahan konsumsi dan produksi menjadi penting (Richards, 1996: 267). Konsumsi dan produksi erat kaitannya dengan segmentasi pasar maka Desa Lingga seharusnya sudah lakujual. Apalagi, pada masa lalu Desa Lingga pernah menjadi destinasi wisata sangat diminati khususnya wisatawan mancanegara.

Warisan budaya (heritage) harus dikembangkan dan dikemas dalam sebuah produk baru agar layak dijual, konsep ini sebenarnya juga merupakan wahana pelestarian. Pengembangan produk baru dimaksudkan sebagai penyesuaian segmentasi pasar pariwisata serta mengikuti kecenderungan yang berubah-ubah. Pariwisata kini didominasi kaum tua (older people) mereka menyukai segala sesuatu yang berkaitan dengan masa lampau (Surbakti, 2004). Autentisitas dan originalitas benda-benda masa lampau itu menjadi hal penting di dalamnya. Segmentasi ini mengarah kepada pengembangan pariwisata budaya yang sedang mendapat tempat dalam pasar pariwisata global dengan ketertarikan pada warisan budaya.

Surbakti (2012) telah mensosialisasikan pengembangan periwisata budaya ini di Rumah Gerga Desa Lingga dalam sebuah seminar pada acara - Watch Dayll ketika konservasi akan dimulai. Dijelaskan bahwa menurut konsepsi Bourdieu, rumah tradisional Karo di Lingga merupakan modal budaya (cultural capital ) yang dapat ditransformasikan menjadi modal ekonomi (economic capital) dan pada akhirnya dapat menjadi modal simbolik (symbolic capital) yang akan menaikkan pendapatan asli daerah (PAD) masyarakat. Malaysia dan Singapura sebagai contoh, telah berhasil membangun perekonomian negaranya melalui sektor tersier atau jasa pariwisata berbasis warisan budaya.

Kekuatan potensi Desa Lingga sudah selayaknya dikembangkan yaitu selain untuk pengembangan pariwisata budaya juga untuk memperkuat identitas lokal. Kesinambungan masa lalu bila dikaitkan dengan kecenderungan masa kini dan masa yang akan datang, menjamin kebermanfaatan produk budaya masa lalu itu dalam bidang ekonomi. Dunia kini telah memasuki gelombang keempat peradaban manusia dengan konsepsi pengembangan 
ekonomi kreatif. Pengembangan ekonomi kreatif sendiri pada hakekatnya antara lain berbasis warisan budaya, lingkungan, dan ekonomi kepariwisataan. Oleh sebab itu, Desa Lingga perlu mendapat perhatian serius agar tidak ada lagi rumah tradisional yang rubuh

\section{Pembahasan}

Dewasa ini aktifitas pariwisata cenderung semakin meningkat dan merupakan salah satu industri terbesar di dunia dan dianggap merupakan komoditi ekonomi dengan prospek cerah pada masa depan. Banyak negara mempersiapkan diri dengan melakukan pelbagai kebijakan dalam konteks membangun industri pariwisata termasuk Indonesia. Pariwisata menjadi penting dalam membangun perekonomian Indonesia seiring dikeluarkannya kebijakan yang ditandatangani mantan Presiden Susilo Bambang Yudhoyono yaitu konsep pembangunan ekonomi kreatif berdasarkan pengembangan pariwisata budaya. Kebijakan kepariwisataan Indonesia ini dituangkan dalam Peraturan Pemerintah Republik Indonesia Nomor 5 Tahun 2011 Tentang Rencana Induk Pembangunan Kepariwisataan Nasional (RIPPARNAS) Tahun 2010-2025.

Kebijakan dalam RIPPARNAS ditindaklanjuti pemerintah yaitu dengan mengeluarkan salah satu agenda kebijakan dalam pelestarian rumah tradisional di Indonesia. Sehingga,banyak rumah tradisional sekarang ini dilestarikan dalam kepentingan pengembangan pariwisata. Pemerintah Kabupaten Karo juga sedang melakukan pendataan sebaran rumah tradisional Karo di Tanah Karo yang jumlahnya tidak banyak lagi. Masih ada tersisa sedikit di beberapa desa. Rumah tradisional Karo di Desa Lingga memiliki estetika berbeda dengan rumah tradisional lainnya. Dikatakan berbeda karena sejarah panjang dan tingginya peradaban nenek moyang masyarakat Desa Lingga yang tinggalannya masih dapat dilihat sekarang ini merupakan warisan luhur para leluhur yang harus dilestarikan.

Setelah selesai dikonservasi pada tahun 2014, bangunan tradisional dan rumah tradisional Lingga belum dimanfaatkan sebagaimana mestinya. Geriten sebagaimana fungsinya tetap seperti semula, Sapo Ganjang saat ini dalam keadaan terbengkalai dan dipenuhi barang-barang, Rumah Belang Ayo saat ini dihuni keluarga dan cenderung kurang terawat, sedangkan Rumah Gerga sering kosong karena ditinggalkan penghuninya. Potensi sumber daya budaya Desa Lingga mengalami degradasi. Demikian juga dengan potensi sumber daya manusia yang perlahanlahan mulai meninggalkan aktifitas seni dan budaya karena dianggap tidak akan merubah kebutuhan ekonomi mereka. Walau demikian, sekarang ini masih terdapat sebuah sanggar seni yang mencoba bertahan walau cenderung selalu sepi dari pesanan barang atau jasa.

Segmentasi pasar pariwisata global saat ini didominasi pariwisata budaya. Pengertian pariwisata budaya menurut Boniface (1995: 115) adalah jenis kepariwisataan yang berhubungan dengan kehidupan manusia dan cara hidupnya serta hasil karyanya, teristimewa hasil karya pada jaman dahulu. Sementara itu menurut Borley (1996: 181), menjelaskan bahwa pariwisata budaya merupakan aktifitas yang memungkinkan wisatawan untuk mengetahui serta memeroleh pengalaman secara langsung tentang perbedaan cara hidup orang lain, mempelajari refleksi adatisatiadatnya, nilai filosofi dan tradisi religiusnya, dan ide-ide intelektual dalam warisan budaya yang belum dikenal di tempat yang dikunjunginya. Persis seperti pendapat Richards (1996) masalah konsumsi dan produksi di Desa Lingga merupakan hal penting.

Batasan pengertian pariwisata budaya di atas sesuai dengan pengembangan Desa Lingga menjadi objek pariwisata budaya dengankomponen budaya yang dimiliki. Sumber daya budaya adalah bukti sejarah dan bendabenda sarat makna semiotik yang dapat membantu ingatan kita dalam memahami suatu objek. Masyarakat Desa Lingga pada umumnya mahir dalam bidang anyaman, tari,ndikar, ukir, pahat, dan pembuatan alat-alat musik tradisional. Hal ini sesuai dengan komponen budaya yang menjadi daya tarik wisatawan (menurut Richie dalam Shaw dan Williams, 1997) yaitu (1) kerajinan, (2) tradisi, (3) sejarah suatu tempat, (4) arsitektur, (5) makanan tradisional, (6) seni dan musik, (7) cara hidup masyarakat, (8) agama, (9) bahasa, dan (10) pakaian tradisional.

Desa Lingga saat ini mengalami kelesuan pasar dan salah satu penyebabnya adalah stagnansi produk dan jasa yang dijual. Akan tetapi, pemilik sanggar yaitu Pusen Sinulingga (38 tahun) justru sering mendapat pesanan dari luar desa untuk mengisi acara dalan pelbagai event. Salah satu atraksi yang paling populer adalah ndikar yaitu silat tradisional Karo. Sumber daya budaya ini harus dimodifikasi. Menurut ekonomi makro, apabila suatu produk sudah mengalami stagnansi maka harus diciptakan produk baru untuk menggantikan produk yang sedang berjalan agar bisa 
merebut pasar. Diperlukan upaya-upaya modifikasi. Masyarakat Desa Lingga beserta Dinas Pariwisata Karo harus bekerjasama dalam melahirkan produk-produk baru tersebut.

Kekuatan sumber daya budaya dan sumber daya alam Desa Lingga berbanding lurus dengan kelemahan sumber daya manusianya. Menurut analisis SWOT, strategi yang digunakan berada pada titik kuadran 2 dengan konsepsi =mendukung strategi deversifikasi ‘ di mana konsepsi ini sesuai dengan kebijakan ekonomi makro. Strategi yang dirancang mengikuti pasar pariwisata global yaitu pariwisata budaya dan pengelolaannya berbasis masyarakat.Pembangunan pariwisata berbasis masyarakat mengamanatkan adanya kerjasama antara sumber daya, wisatawan, dan masyarakat lokal. Oleh sebab itu, disusun program pengembangan para pemangku kebijakan terkait yaitu program pengembangan Desa Budaya Lingga sebagai produk baru dalam cakupan luas dan saling terintegrasi dengan batasan pengembangan di bawah ini

Menurut Pitana dan Diarta (2009: 75-76), sumber daya budaya yang dapat dikembangkan menjadi daya tarik wisata pariwisata budaya di antaranya adalah:

- Bangunan bersejarah, situs, monumen, museum, galeri seni, situs budaya kuno, dan sebagainya,

- Seni dan patung kontemporer, arsitektur, tekstil, pusat kerajinan tangan dan seni, pusat desain, studio artis, industri film dan penerbit, dan sebagainya,

- Seni pertunjukan,drama, sendratari, lagu daerah, teater jalanan, eksibisi foto, festival, dan even khusus lainnya,

- Peninggalan keagamaan seperti pura, candi, masjid, situs, dan sejenisnya,

- Kegiatan dan cara hidup masyarakat lokal, sistem pendidikan, sanggar, teknologi tradisional, cara kerja, dan sistem kehidupan setempat,

- Perjalanan (trekking) ke tempat bersejarah menggunakan alat tranportasi unik (berkuda, dokar, cikar, dan sebagainya), dan

- Mencoba kuliner (masakan) setempat. Melihat persiapan, cara membuat, menyajikan, dan menyantapnya merupakan atraksi budaya yang sangat menarik bagi wisatawan.

Lebih lanjut Nuryanti (1996) menjelaskan, dalam pariwisata budaya kebudayaan dimaknai sebagai proses dan produk sekaligus. Sebagai proses, pariwisata budaya merupakan sebuah kegiatan pertukaran informasi dan makna semiotik budaya antara wisatawan yang berkunjung dengan masyarakat di objek wisata. Aktifitas ini membuka kemungkinan terjadinya dialog antar budaya, proses pertukaran ide, memberi sumbangan pemikiran akan timbulnya ide-ide kreatif dan merupakan salah satu sarana untuk meningkatkan saling pengertian dan perdamaian. Sebagai produk, pariwisata budaya menyuguhkan atraksi-atraksi dan benda-benda budaya yang dikemas untuk konsumsi wisatawan. Melalui kemasan ini diharapkan wisatawan memeroleh pengalaman kebudayaan dengan melihat langsung sesuatu yang unik dan berbeda.

Dalam upaya pengembangan atraksi pariwisata budaya di Desa Lingga diperlukan penelusuran dan penulisan ulang sejarah dan kesembilan komponen budaya lainnya. Komponen budaya tersebut mempunyai pelbagai nilai dan makna sesuai konteksnya. Desa Lingga merupakan salah satu desa tertua di daratan tinggi Karo. Sejarah Desa Lingga tidak terlepas dari Kerajaan Linggaraja Pakpak, Dairi, yaitu keturunandinasti Maharaja Agi Sry Timur Raja asal negeri Barus yang keturunannya banyak membuka perkampungan di Tanah Karo.Raja Desa Lingga sendiri merupakan anak Raja Desa Nodi, ia pertama sekali membuka kampung Kuta Suah di lembah uruk Gungmbelin yang kemudian ditinggalkan karena keterbatasan air bersih dan dibuka Desa Lingga yang dikenal seperti sekarang ini.

Desa Lingga dahulu dibagi dalam beberapa sub desa yang disebut kesain. Kesain merupakan wilayah desa yang namanya disesuaikan dengan marga yang menempati wilayah tersebut. Nama-nama kesain di Desa Lingga adalahKesain Rumah Jahe, Kesain Rumah Bangun, Kesain Rumah Berteng, Kesain Rumah Julu, Kesain Rumah Mbelin, Kesain Rumah Buah, Kesain Rumah Gara, Kesain Rumah Kencanen, dan Kesain Rumah Tualah. Demikian tingginya nilai kesejarahan Desa Lingga beserta sumber daya budaya yang melekat sebagai bagian dari peradaban masyarakatnya. Sungguh suatu potensi besar bagi pengembangan pariwisata budaya sehingga perlu dilestarikan.

Nilai dan makna warisan budaya menurut Lipe (1984) terdiri atas (1) bersifat assosiatif karena merupakan media penghubung dengan masa lalu, (2) nilai informatif antara lain berupa keterangan, filosofi, kearifan lokal, dan fungsi warisan budaya, (3) nilai keindahan sebagai bukti tingginya peradaban serta menimbulkan rasa bangga, dan (4) nilai ekonomi yang dihasilkan dari pemanfaatan warisan budaya berupa atraksi bagi wisatawan. Sosialisasi nilai dan 
makna ini perlu dilakukan kepada masyarakat Tanah Karo pada umumnya agar semua orang merasa memiliki dan melestarikan budaya Desa Lingga.

Konsepsi pembangunan pariwisata berbasis kerakyatan (Tourism-Based-Community Development) dari Natori (2001) sangat sesuai untuk pengembangan pariwisata budaya di Desa Lingga. Pemberdayaan masyarakat lokal harus dikedepankan dengan mengikuti Tolok Ukur Pembangunan Pariwisata Berbasis Masyarakat (Natori, 2001: 9). Kelemahan SDM Desa Lingga dalam pengembangan kepariwisataan kasusnya persis seperti dijabarkan Woodley (1992) yaitu (1) masyarakat biasanya tidak mempunyai visi pengembangan, (2) masyarakat kurang memiliki kesadaran peran penting pariwisata, (3) kurangnya SDM kepariwisataan, (4) adanya kesenjangan budaya (cultural barrier) antar masyarakat dengan wisatawan, dan (5) masyarakat tidak mempunyai modal ekonomi dalam pengembangan.

Berdasarkan konseptual industri pariwisata diperlukan beberapa sektor yang bekerja secara integratif dalam membangun kepariwisataan Desa Lingga, yaitu (a) transportasi, (b) akomodasi, (c) biro perjalanan dan tour operator handal, (d) atraksi wisata, (e) pelayanan wisata, dan (f) organisasi kepariwisataan terkait (Ward dalam Ardika , 2007: 34)). Menurut (Nuryanti, 1996: 246 ) dalam tulisannya -Heritage and Postmodern Tourism", nilai ekonomi yang dihasilkannya akan didistribusikan kepada para pelaku industri pariwisata (direct effects), kepada orang yang terlibat dalam industri pariwisata (indirect effects), dan masyarakat luas pada umumnya (induced effects). Pengembangan pariwisata budaya di Desa Lingga secara umum akhirnya akan menaikkan PAD masyarakat Kabupaten Karo.

\section{Penutup}

Bangunan tradisional Karo di Desa Lingga, Kabupaten Karo, memiliki potensi besar untuk dikembangkan menjadi objek pariwisata budaya. Banyak kelemahan dikandung objek sehingga mengalami degradasi nilai, oleh sebab itu perlu dikembangkan menjadi sebuah produk baru untuk mengantisipasi kecenderungan pariwisata global. Konsepsi pembangunan digunakan model bottom-up (dari bawah ke atas) bukan top-down (dari atas ke bawah) yang sering merugikan masyarakat. Demikian juga dengan Tolok Ukur Pembangunan Pariwisata Berbasis Msayarakat yang mengamanatkan harmonisasi antara sumber daya, masyarakat lokal, dan wisatawan.Sinergitas kerjasamaantar sektor kepariwisataan diperlukan untuk mewujudkan strategi pengembangan. Akhirnya terbuka peluang besar bagi masyarakat Desa Lingga dalam menciptakan pembangunan ekonomi kreatif berbasis seni dan budaya yang masih digalakkan pemerintah sampai saat ini.

\section{Daftar pustaka}

[1] Ardika, Wayan I. 2003. Pariwisata Budaya Berkelanjutan, Refleksi dan Harapan di tengah Perkembangan Global. Denpasar: Program Studi Magister (S2) Kajian Pariwisata.

[2] Bungin, Burhan. 2007. Penelitan Kualitatif. Komunikasi, Ekonomi, Kajian Publik, dan Ilmu Sosial Lainnya. Jakarta: Kencana Prenada Media Grup.

[3] [Cartier, C. 1996. "Conserving the Built Environment and Generating Heritage Tourism in Peninsular Malaysia", Tourism Research 21, I, hlm. 45-53.

[4] 1998. "Megadevelopments in Malaysia: From Heritage Landscapes to Leisurescape in Melaka's Tourism Sector", Singapore Journal of Tropical Geography 19, 2, hlm. 151-176. Ginting, Biak Ersada. 2002. Sejarah Perjuangan Suku Karo dan Dari Perang Medan Area Hingga Sipirok Area. Medan: Ravi Bina.

[5] Hacker, Richard, Cheelen Mahar, dan Chris Wilkes (eds.). 2005. (Habitus X Modal) + Ranah = Praktik, Pengantar Paling Komprehensif kepada Pemikiran Pierre Bourdieu (terjemahan). Yogyakarta: Jalasutra.

[6] Jennings, Gayle. 2010. Tourism Research, Wiley Australian Tourism Series. China: Printing International. Kantor Menteri Negara Lingkungan Hidup dan United Nations Development Programme. 2001. Agenda 21 Sektoral. Agenda Pariwisata untuk Pengembangan Kualitas Hidup Secara Berkelanjutan. Lubis, Akhyar, Yusuf. 2006. Dekonstruksi Epistemologi Modern, Dari Posmodernisme, Teori Kritis, Poskolonialisme hingga Cultural Studies. Jakarta: Pustaka Indonesia Satu.

[7] Masahiko, Natori. 2001. A Guide Book for Tourism-Based Community Development. Osaka : Asia Pacific Tourism Exchange Center (APTEC).

[8] Nuryanti, Wiendu. 2009. - Sinergi Arsitektur dan Pariwisata dalam Membangun Indonesia Kreatif", Pidato Pengukuhan Jabatan Guru Besar pada Fakultas Teknik Universitas Gadjah Mada, Yogyakarta. 
[9] 1996. - Heritage and Postmodern Touridm" dalam Geofrrey Wall dan Wiendu Nuryanti (eds). Heritage and Tourism, Special Issue, Annals of Tourism Research A Social Sciences Journal Volume 23 Number 2 ISSN: 0160-7383, hlm. 249-260.

[10] Peraturan Pemerintah Republik Indonesia No.5 Tahun 2011 Tentang Rencana Induk Pembangunan Kepariwisataan Nasional (RIPPARNAS) Tahun 2010-2025.

[11] Perlas, Nicanor. 2000. Shapping Globalization Civil Society, Cultural Power and Threefolding. New York Centre for Alternative Development Initiatives (CADI) and Global Network for Social Threefolding (GlobeNet3).

[12] Pitana dan Diarta. 2009. Pengantar Ilmu Pariwisata. Yogyakarta: ANDI.

[13] Prentice, R. 1995. Tourism and Heritage Attractions. London: Routledge.

[14] Putro, Brahma. 1997. Karo dari Zaman ke Zaman. Medan: Ulih Saber.

[15] Rata, Ida Bagus. 1993. - Manfaat Peninggalan Arkeologi Untuk Kepentingan Agama, Sosial Budaya,

[16] Sosial Ekonomi, Pendidikan, dan Ilmu Pengetahuan". Makalah Dalam Rangka Menyambut Purnabakti Prof. Dr. Ida Bagus Mantra, Fakultas Sastra Universitas Udayana, Denpasar, Bali. Richards,

[17] G. 1997. — The Social Context of Cultural Toursim" dalam Greg Richards (ed.) Cultural Tourism in Europe. Wallingford, UK: (AB International hlm. 47-70.

[18] 1997. Cultural Tourism in Europe. UK: Biddles Ltd.

[19] Seminar Arsitektur Angkatan XXV (NN). Arsitektur Tradisional Sebagai Perwujudan Budaya. Studi Kasus: Arsitektur Tradisional Batak Karo.

[20] Shaw, Garet and A.M. Williams. 1997. The Earthscan Reader in Sustainable Tourism. pp 106-112. London: Earthscan Publication.

[21] Surbakti, Asmyta. 2012. - Desa Lingga sebagai Objek dan Daya Tarik Wisata Pariwisata Posmodern". Makalah pada Seminar Internasional Pelestarian Budaya Karo, Watch Day 2012 Desa Lingga, 30 Oktober 2012.

[22] 2010. Pengembangan Kawasan Bersejarah Lapangan Merdeka dalam Konteks Industri Pariwisata di Kota Medan. Laporan Penelitian Lembaga Penelitian Universitas Sumatera Utara dengan Dana Masyarakat Lembaga Penelitian Universitas Sumatera Utara.

[23] 2004."Konservasi dan Pengembangan Kawasan Bersejarah Istana Maimoon dalam Konteks Industri Pariwisata di Kota Medan, Tesis Magister (S2) Program Pascasarjana Universitas Udayana, Denpasar, Bali.

[24] Suwantoro, Gamal. 1997. Dasar-Dasar Pariwisata. Yogyakarta: ANDI.

[25] Tjahyadi, Sindung. 2003. - Ilmu, Teknologi, dan Kebudayaan" dalam Tim Dosen Filsafat Ilmu Fakultas Filsafat UGM, editor. Filsafat Ilmu Sebagai Dasar Pengembangan Ilmu Pengetahuan. Yogyakarta: Liberty.

[26] Yoeti, Oka. A. 1996. Perencanaan dan Pengembangan Pariwisata. Jakarta: PT. Pradnya Paramita. 